This item was submitted to Loughborough's Research Repository by the author.

Items in Figshare are protected by copyright, with all rights reserved, unless otherwise indicated.

\title{
Balancing mission creep, means, effectiveness and legitimacy at the World Anti-Doping Agency
}

PLEASE CITE THE PUBLISHED VERSION

https://doi.org/10.1016/j.peh.2020.100175

PUBLISHER

Elsevier

VERSION

AM (Accepted Manuscript)

\section{PUBLISHER STATEMENT}

This paper was accepted for publication in the journal Performance Enhancement \& Health and the definitive published version is available at https://doi.org/10.1016/j.peh.2020.100175.

\section{LICENCE}

CC BY-NC-ND 4.0

\section{REPOSITORY RECORD}

Read, Daniel, James Skinner, Daniel Lock, and Barrie Houlihan. 2020. "Balancing Mission Creep, Means, Effectiveness and Legitimacy at the World Anti-doping Agency". Loughborough University. https://hdl.handle.net/2134/13235300.v1. 
Title: Balancing Mission Creep, Means, Effectiveness and Legitimacy at the World AntiDoping Agency

Daniel Read ${ }^{\mathrm{a}}$, corresponding author d.read3@lboro.ac.uk

James Skinner $^{\mathrm{a}}$

Daniel Lock ${ }^{\mathrm{b}}$

Barrie Houlihan ${ }^{\mathrm{c}, \mathrm{d}}$

${ }^{a}$ Loughborough University London, London, UK

${ }^{\text {b} B o u r n e m o u t h ~ U n i v e r s i t y, ~ F e r n ~ B a r r o w, ~ P o o l e, ~ U K ; ~}$

${ }^{c}$ Loughborough University, Loughborough, UK

${ }^{\mathrm{d}}$ Norwegian School of Sport Sciences, Oslo, Norway

Declarations of interest: none. 
Abstract: Established in 1999, the World Anti-Doping Agency (WADA) was an ambitious project to harmonise anti-doping regulations globally. Since its creation, WADA has engaged in additional activities such as investigating doping allegations, managing whistleblowers and coordinating with national and international customs organisations. These activities demonstrate 'mission creep', a term denoting that WADA's purpose has broadened from its original responsibilities. Lawrence (2008) argues that the relationship between an international non-governmental organisation's legitimacy to regulate an issue and mission creep is related to its means (i.e., physical and non-physical resources) and effectiveness. This article explores how WADA's mission creep has influenced its perceived legitimacy as the regulator of anti-doping, globally. Following analysis of 14 interviews with occupationally and globally diverse anti-doping professionals, three themes were identified: code implementation, representation, and conflicts of interest. It is argued that the legitimacy of WADA to regulate anti-doping has been weakened due to tensions created by responding to emerging challenges in order to maintain legitimacy, whilst trying to secure means. These tensions have diverted resources to new activities and, therefore, reduced WADA's effectiveness in other activities; paradoxically undermining its legitimacy. Consequently, it is advised that WADA prioritises its responsibilities, looks for additional sources of means and addresses democratic deficiencies.

Key words: Anti-Doping; WADA; Legitimacy; Mission Creep; World Anti-Doping Code. 


\section{Introduction}

The World Anti-Doping Agency (WADA) was created in 1999 as a hybrid organisation of national governments and the Olympic movement with the core mission of harmonising antidoping policy between nations and international federations to protect athlete welfare and sporting integrity. A central feature of this original mission is the World Anti-Doping Code (the Code), a living policy document that stipulates the requirements of all signatories. The Code also highlights responsibilities that fall under WADA's remit to lead a collaborative worldwide movement for doping-free sport. Throughout the course of its existence, WADA has responded to a dynamic environment in which scandals have revealed new doping practices challenging its legitimacy (Dimeo \& Møller, 2018; Hunt, 2011; Read et al., 2019). Consequently, WADA's responsibilities have extended into new areas, such as educating athletes on anti-doping, managing whistle-blowers, investigating signatory compliance, and coordinating strategies with national and international public authorities (e.g., Interpol) to deal with drug-trafficking (Erickson et al., 2018; Girginov \& Parry, 2018; Weber et al., 2015). It could be argued, therefore, that WADA's expanding activities constitute mission creep (Lawrence, 2008).

Mission creep refers to situations in which an organisation purposefully undertakes additional responsibilities for issues not previously considered within their remit, as opposed to organisational adaptation which involves reactively implementing new behaviours in response to environmental changes to fulfil existing responsibilities. Using the World Trade Organisation as an example, Lawrence (2008) argues that (i) mission creep, (ii) the means (i.e., physical and non-physical resources) with which an international non-governmental organisation (INGO) is provided, and (iii) the organisation's perceived effectiveness are all related to its legitimacy for two reasons. Firstly, when an INGO is evaluated as legitimate, stakeholders judge that it has appropriate authority to impose rules and govern, which leads 
to compliance (Hurd, 1999). Secondly, as an INGO's mission creeps and it takes on new responsibilities, it requires additional means to effectively execute existing and new functions. The requirement for additional means creates two legitimacy challenges. If an INGO is provided with insufficient means, it is likely to be ineffective in executing existing and new responsibilities, and therefore lacking legitimacy to impose rules and govern. In contrast, if an INGO is provided with increased means to accomplish new responsibilities its processes and effectiveness receive greater scrutiny to assess if the increased means are justified, and whether the organisation is legitimate to regulate the issue. Lawrence (2008) argues that all INGOs face the dilemma of balancing legitimacy, mission creep, effectiveness, and means as they work to satisfy the responsibilities and expectations of different stakeholders.

In this paper, we apply Lawrence's (2008) dilemma and argue that WADA's expanding responsibilities in response to emerging challenges are a pertinent example of mission creep from its original mission of harmonisation. As a result, WADA requires increased means to effectively execute both new and existing responsibilities. To date there has been no empirical study of how WADA's mission creep, means and effectiveness has influenced evaluations of its legitimacy. Perceived legitimacy is integral to all INGOs as it fosters behavioural support from signatories in lieu of coercive powers available to national governments (e.g., surveillance; Beetham, 2013; Hurd, 1999). Further, there remains a need for empirical studies that examine how external audiences perceive an organisation's legitimacy in relation to mission creep (Klein, Schneider \& Spieth, 2020). Accordingly, this study explores how anti-doping professionals perceive the relationship between WADA's mission creep, means, effectiveness, and legitimacy.

This paper's contribution is threefold. First, it is argued that WADA's mission creep has weakened its legitimacy because diverting limited means to new challenges has reduced 
the organisation's effectiveness in relation to original responsibilities; a tension exacerbated by operating with inadequate means. Secondly, an initial set of themes are provided to understand how anti-doping professionals evaluate the legitimacy of WADA for future research. Lastly, we argue that Lawrence's (2008) mission creep dilemma should be developed to acknowledge a situation where an INGO may be considered legitimate despite ineffectiveness because the organisation is perceived as preferable to previous regulatory approaches.

\section{A Social Judgements Approach to Legitimacy}

Legitimacy is a central tenet of institutional theory (Bitektine \& Haack, 2015; Washington \& Patterson, 2011) and understanding how organisations such as INGO's achieve behavioural support (Beetham, 2013; Lawrence, 2008). From a social judgements perspective legitimacy is "the perceived appropriateness of an organization to a social system in terms of rules, values, norms, and definitions" (Deephouse et al., 2017, p. 32). This definition reflects our theoretical positioning that legitimacy should be treated as a contextual judgement bestowed on organisations by the individuals and groups they govern (Bitektine, 2011; Lock et al., 2015; Tost, 2011). Conceptualising legitimacy as a judgement invokes a position that individuals and groups evaluate the propriety of an organisation's aims, characteristics, processes, structures, behaviours and outcomes (Bitektine, 2011). The positive or negative valence of this judgement partly determines how an individual or group will behave in relation to the organisation (e.g., endorsement or avoidance). An evaluator will also consider how they perceive other relevant stakeholders have judged an organisation's legitimacy (Bitektine \& Haack, 2015). If other significant sources judge the organisation positively, an evaluator is more likely to endorse the organisation regardless of their own judgement (Haack, Schilke \& Zucker, 2020). Through the collective consensus of personal 
and social judgements in a field between individuals and groups, an organisation's legitimacy is determined.

\subsection{The Legitimacy of WADA}

There is a body of research that investigates how athletes evaluate WADA and its anti-doping practices (e.g., Efverström et al., 2016a, 2016b; Gucciardi et al., 2010; Henning \& Dimeo, 2019). Interest in athlete perceptions is congruent with predictive models of doping, which theorise that perceptions of legitimacy influence athletes' attitudes and behaviours towards doping in sport (e.g., Donovan et al., 2002). The evidence about whether legitimacy improves athlete compliance with anti-doping rules, however, is unclear (Gucciardi et al., 2010; Jalleh et al., 2014). Studies of athlete judgements of legitimacy have indicated support for the idea of anti-doping; however, there is evidence that experiences of inequitable implementation undermine evaluations of legitimacy and athlete support (e.g., Bloodworth \& McNamee, 2010; Efverström et al., 2016a, 2016b; Henning \& Dimeo, 2019; Overbye \& Wagner, 2014; Woolway et al., 2020). Nevertheless, there is no previous research that addresses how anti-doping professionals judge the legitimacy of WADA. Given that legitimacy fosters compliance and support, studying how anti-doping professionals perceive the legitimacy of WADA is critical to understanding behavioural support for the organisation.

In addition to studying WADA's perceived legitimacy, research has addressed how WADA has managed its legitimacy. McDermott (2015) has argued that portraying doping in sport as a legitimacy crisis and moral panic is one strategy WADA and the International Olympic Committee (IOC) used to retain control of the issue. Toohey and Beaton (2017) examined how WADA has responded to economic and social constraints throughout its existence, finding that "legitimacy was the only theme present across the three phases of WADA, reinforcing the assertion that the key to organizational survival is acquiring and 
maintaining legitimacy" (p. 494). Qvarfordt et al. (2019) studied the discourses used by WADA to legitimate anti-doping efforts in athlete anti-doping guides. They found that WADA has slowly moved away from an authoritarian approach to include instrumental arguments to legitimate anti-doping. Qvarfordt et al. (2019) summarise WADA's approach as "a turn away from the earlier focus on prohibition, suspicion and fighting, and towards protecting the clean athlete, in a seemingly carefully considered way" (p. 6). Lastly, Read et al. (2019) demonstrated how WADA's behaviour, direction, and policies may be influenced by the need to satisfy expectations of legitimate behaviour, rather than proactive decisionmaking.

Together these articles demonstrated that WADA: (i) acknowledges the value of legitimacy in accruing behavioural support to govern, (ii) recognises the need to maintain access to the resources it commands, and (iii) uses strategic action and discourse to influence perceptions of its legitimacy. Yet, there remains an absence of studies examining how antidoping professionals perceive the legitimacy of WADA and how this may influence support for the organisation.

\subsection{WADA's Mission Creep, Means, Performance and Legitimacy}

There is limited work involving the concept of mission creep in relation to sport policy. Hanstad and Houlihan (2015) treated mission creep as the final stage of a policy regime's development as an organisation reinvents itself and purpose. Likewise, Harris and Houlihan (2015) explained mission creep as an inclination to extend original activities into the tasks of other organisations. This accords with Lawrence's treatment of mission creep as the tendency for INGO to adopt new responsibilities. Pertinent to the current study, Waddington and Møller (2014) argued that the definition of doping was redefined by WADA so that non-performance enhancing recreational drugs which presented a risk to the image of 
sport could be prohibited. In redefining doping, WADA's mission purposefully crept as it took responsibility for regulating athlete behaviours outside of athletic competition. WADA's original mission was to harmonise anti-doping regulation and mission creep is visible as the organisation has had to take on additional responsibilities in response to emerging challenges(Dimeo \& Møller, 2018; Girginov \& Parry, 2018; Read et al., 2019; Weber et al., 2015).

Lawrence (2008) suggests three reasons why mission creep may occur in an INGO. Firstly, an INGO can be pressured by stakeholders to address emerging issues. Secondly, an INGO can develop its' own agenda and self-determine which activities to pursue. Lastly, an INGO may adopt new tasks as it succeeds in previous activities or is presented with new challenges, until it reaches a level of responsibility beyond its' capabilities. Whether mission creep impacts legitimacy negatively or positively is determined by an organisation's physical (e.g., funding) and non-physical (e.g., expertise) means and its perceived effectiveness in executing existing and new responsibilities. If an INGO does not have adequate means to fulfil existing responsibilities and accomplish new tasks, then it is unlikely to be effective, thus undermining its legitimacy. Equally, increased provision of means is accompanied by greater stakeholder expectations of performance and influence over the INGO's agenda and direction. Lawrence (2008) outlines the dilemma INGOs face:

If missions are expanded, and organizations given insufficient means, they are likely to fail (or fall short of optimal behavior) and be criticized for ineffectiveness.

However, the more extensive the means they are given, the more likely that their legitimacy will be questioned (p. 1461).

Therefore, changes to an INGO's mission, deliberate or unintentional, can create challenges to perceived legitimacy to govern and regulate an issue. 
Applying Lawrence's (2008) INGO legitimacy dilemma, if WADA's mission creep has undermined perceptions of its legitimacy, behavioural support from sources will be diminished (Suddaby, Bitektine \& Haack, 2017), and the success of WADA threatened. Therefore, understanding WADA's mission creep is fundamental to engaging behavioural support from stakeholders and the ultimate ambitions of the anti-doping movement.

Consequently, we explore the following research question: how has WADA's mission creep influenced perceptions of its legitimacy?

\section{Method}

\subsection{Research Philosophy}

The contributions to institutional theory (Meyer \& Rowan, 1977; Zucker, 1977) are grounded in Berger and Luckmann's (1967) work on the social construction of knowledge. In this work, Berger and Luckmann argue that subjective beliefs take on an objective nature over time through the repetition and sedimentation of behaviour. Therefore, institutions and the legitimacy that they depend upon for stability, are socially constructed. Given the socially constructed nature of legitimacy judgements (Suddaby et al., 2017), and the existence of multiple truths and realties about WADA based on an individual's experience, a constructivist paradigm was adopted with a cross-sectional qualitative research design. Following a constructivist paradigm, the analysis privileged the participants contextual experiences and understanding as evaluators of WADA's legitimacy.

\subsection{Sample}

Purposeful sampling was employed to select information rich participants (i.e., antidoping professionals) to gain insight into mission creep and perceptions of WADA's legitimacy. We sampled participants that had (i) an active role in the anti-doping system 
(organisation executive, technical role, athlete representative or journalist), and (ii) level of expertise on anti-doping (holding or held a senior position in the field, involved in the Code review process, previously subject to anti-doping processes or five or more years commentating on anti-doping). Participants were selected from a range of roles within antidoping to reflect the diversity of actors in the field. In total, 14 interviews were conducted with anti-doping sources including representatives from international federations, national anti-doping organisations (NADO), regional anti-doping organisations (RADO), laboratories, arbitration, journalism, athlete unions and national governments. In terms of the sample, participants had mixed experiences of working in Europe $(n=13)$, North America $(n=3)$, Central and South America $(n=2)$, Africa $(n=3)$, and Asia $(n=3)$. The geographic diversity of occupational experience is a strength of the sample that helps challenge the typical Eurocentric perspective on anti-doping (Loland \& McNamee, 2019). It was also considered a strength of the study that reoccurring dimensions related to the legitimacy of WADA were reiterated by sources with experiences of anti-doping roles in different continents.

Adequate sampling was determined by reaching data saturation (i.e., informational redundancy) to support theoretical generalisations (Andrade, 2009; Francis et al., 2010). Data saturation was judged in this research using the criteria that no new data, coding or themes were apparent in the interviews, and replication of the study would produce similar findings (Guest, Bunce \& Johnson, 2006). Following Francis et al. (2010) suggestion, an initial sample analysis was conducted to assess saturation followed by analysis of further interviews assessing the extent to which new information emerged. After eight interviews, initial analysis was conducted, followed by a review of whether subsequent interviews were adding new themes. New themes were not being identified in the data after 14 interviews.

\subsection{Interview Process}


Participants were required to engage in a semi-structured interview about anti-doping and WADA, which was subsequently analysed using a legitimacy theory lens. The interview was recorded and then transcribed in accordance with ethical approval. Due to the global nature of the sample, two interviews were conducted in person, six by video call, and six by phone. Interpretive questions were used to ensure that the participant's point was fully articulated and synchronous communication for all interviews were used to reduce potential bias between interview method (Lo Iacono, Symonds \& Brown, 2016; Opdenakker, 2006).

\subsection{Data Analysis}

The data were analysed inductively using thematic analysis to identify and report patterns (Braun \& Clarke, 2006). The process of thematic analysis employed in the research had five stages (Clarke \& Braun, 2013). Stage one is familiarisation, which involves transcribing and reading the data. Stage two is coding, which includes conceptual labelling and sorting data to enable stage three, which is the generation of latent themes throughout the dataset. Data were analysed through the lens of legitimacy judgement theory to understand how participants appraised different facets of WADA's legitimacy based on their context and experience. Stages four and five involved reviewing each theme's appropriateness to the research question and data and creating appropriate definitions. The result of the analysis were three themes consisting of nine sub-themes that pertained to WADA's legitimacy as judged by anti-doping professionals. The inductive coding process within this thematic analysis was data-driven and led to information being initially sorted by practical concepts (Nowell et al., 2017) and then subject to focussed coding to critically generate themes under latent titles (Saldaña, 2015). Therefore, the three overarching themes that emerged are contextual rather than grounded in theory. Member-checking was also undertaken to ensure the accuracy of data and thematic inferences. 


\subsection{Limitations}

All the participants interviewed were of the view that anti-doping policy was required, however, it was acknowledged that there were other individuals in the field who may not be supportive of the work of WADA. Moreover, some individuals within the field of anti-doping may currently benefit from the lack of effectiveness. Therefore, all recommendations and findings are from the position that anti-doping is required in sport and are aimed at WADA achieving its goal of harmonising anti-doping policy.

\section{Findings and Discussion}

\subsection{Code Implementation}

Our first theme, Code implementation, brought together perceived issues under the sub-themes: (1) application of the Code globally, (2) sanctioning, (3) testing, and (4) investigations. Participants who had previous experience with code implementation for NADOs and sports organisations recognised that, despite shortcomings with certain aspects of the Code, it had been beneficial overall and should not be discarded. For example, participant seven noted how the Code provided legal support to enforce anti-doping stating, "As President of an international federation it was incredibly important and useful to me to be able to know I had the strength of an international body behind me in trying to implement the rules". Participant nine also appreciated the benefit of guidance provided by the Code to ensure equal treatment stating, "To have an anti-doping policy that was aligned so that you didn't have a different rule for some athletes and also other athletes, and it would've gotten me into a horrible mess". The original mission of standardisation brought about through the Code informed perceptions that WADA was/is legitimate in different stakeholder groups. It is WADA's ineffectiveness and lack of attention to standardisation as the organisation has responded to new responsibilities which has challenged its' legitimacy. 


\subsubsection{Application of the Code Globally}

As the number of activities WADA is responsible for has increased, its legitimacy has been challenged because of perceived ineffectiveness in dealing with regional inconsistencies in policy implementation. Policy harmonisation between regions and sports was the original core mission of WADA. Yet there was a consensus between participants that harmonisation is still a major issue. Disparities in anti-doping controls between signatories creates opportunities for athletes to dope as participant eight explained,

There were athletes in [country removed] that I know were not the clean athletes and one of the strategies of these athletes was, even with the whereabouts system, was to go to parts of Africa where they know it was very difficult to have a doping control performed.

Using the biological passport (a longitudinal record of an athletes physiological markers designed to detect unnatural fluctuations) as an example, participant eight highlighted the problem of replicating testing in countries outside of the global north due to the lack of laboratories in certain regions. WADA's legitimacy is therefore contingent on ensuring antidoping controls and the Code being equally applied across regions. Participant one, who had experience of working in Africa referenced the challenges of implementing the whereabouts system which enables athletes to be tested randomly out-of-competition in the African context. They stated,

In Europe and America one can give an address that is specific to the street... In [country removed] there are hardly buildings that are numbered, even some street names on certain streets ... It gets even worse where when it gets into rural areas where majority of the athletes are based. 
Participants with experience of anti-doping in different regions through work and competition explained that WADA's lack of response to regional policy implementation differences such as the whereabouts system undermines the anti-doping system. The lack of response, in turn, led to negative judgements of WADA's legitimacy. As participant 13 explained, "When you have an organisation with many signatories at different stages, you're only as strong as the weakest signatory". Consequently, as standardisation between signatories is WADA's primary and original mission, as predicted by Lawrence (2008), creep from this mission and ineffectiveness in executing its purpose has undermined WADA's legitimacy to regulate the issue in the eyes of some stakeholders.

Another aspect of Code implementation perceived by participants as a challenge to WADA's legitimacy was the uniform implementation of the therapeutic use exemption (TUE) system. TUEs permit athletes to use substances to treat a medical condition that also have a potential ergogenic benefit. Concerns about TUEs again centred on consistency across regions. Participants from anti-doping organisations articulated concerns about variations in interpretation and decision-making rather than the TUE rule itself. For example, participant 11 who has experience working with NADOs stated, "it's [TUE] implemented very differently across the globe and it's a potential risk for efficient anti-doping”, while participant five added, "They [WADA] have to address the issues, because the misuse of medication because people want to dope themselves is clear and I have a feeling that the current system in place is not the best". It appears that inconsistencies in the current TUE system that could be exploited and the lack of response to implementation of the TUE system presents legitimacy challenges to WADA from individuals with experience of implementation in different regions. This reflects the dilemma posed by Lawrence (2008) because while WADA's responsibilities have increased to consider new challenges, it has 
failed to regulate activities central to its original mission. Consequently, the experiences of inconsistent implementation of TUEs in different regions undermine WADA's legitimacy.

\subsubsection{Sanctioning}

There was a general negative consensus described by participants about WADA's lack of concern for the human rights of athletes punished for recreational and inadvertent use of substances sanctioned under strict liability in the Code. Participant four summarised this stating,

You know large amounts of doping goes undetected. Certainly, the kind of RUSADA [Russian Anti-Doping Agency] scandal has brought that to light... But at the same time a significant amount of resources is going into catching athletes where they clearly hadn't intended to cheat. And I kind of think the fundamental issue that should be at the heart of the anti-doping movement is catching cheats and too often it's picking up on an inadvertent and technical rule violations.

Our results indicate that if WADA is unable to effectively detect and sanction clear cases of cheating whilst athletes who make mistakes and gained no advantage are punished, perceptions of the organisation's legitimacy will be negative. This concern was reflected in perceptions of the legitimacy of imposing sanctions for the use of recreational drugs or inadvertent anti-doping rule violations and the potential conflict with the human rights of athletes. As participant six stated, "if you can prove that it wasn't in competition and actually you were kind of like, it was indirect and you didn’t have a clue what you were doing. You still get that two-year ban". In addition to the legitimacy challenges this creates due to the diversion of limited means away from other anti-doping efforts, the sanctioning of athletes for recreational substances and (proven) inadvertent use contravened ethical expectations again indicating a lack of response to issues critical to WADA's mission. At the heart of 
WADA's original mission to harmonise anti-doping is the equal and fair treatment of athletes a point upon which the organisation's legitimacy depends. Against the backdrop of an organisation that has focused on expanding responsibilities in relation to compliance monitoring, the inactivity and ineffectiveness in response to growing concerns about human rights was articulated by participants as a challenge to the organisation's legitimacy. As participant four stated "this kind of very rigid approach to code enforcement, the whole kind of culture underpinning that has to shift to a sort of more holistic kind of appreciation of the rights of the athletes". Evidently, responding to proportionality of sanctioning should be a central concern for WADA.

\subsubsection{Testing}

A major issue with Code implementation was the perceived ineffectiveness of testing which has undermined WADA's legitimacy in the eyes of participants. Testing has been the cornerstone of anti-doping efforts under WADA, yet collectively participants explained that it has been ineffective at deterring or detecting doping compared to the costs. As participant 11 explained from their experience of NADO operations,

We have seen at least internationally that many athletes who have been tested quite substantially have not tested positive but then have doped significantly during their career ... Testing is really in many instances in some areas inefficient and waste of resources.

This quote is typical of a perception that testing was not catching athletes with sophisticated doping programmes. For anti-doping organisations that have limited means, testing ineffectiveness and perceived waste of resources are significant challenges to WADA's legitimacy. WADA's legitimacy was also undermined by the perception that doping is far 
more widespread than testing statistics suggest. For example, participant 14 stated from their experience with anti-doping organisations,

We have seen in the last three or four years that the positive tests rates internationally are around $1.7-2.0 \%$ tops. So, one test depending on the country, and whatever that test costs, maybe 200 dollars or more or less, so it's a lot of money that has just been blown away.

Although WADA is not responsible for testing, participants explained that diversion of means at WADA contributed to the problem. As participant 10 highlighted about WADA's allocation of funding for research testing, “... an 80 percent decline in the amounts of money on researching new testing techniques ... because they've [WADA] had to divert so much money into investigations and other things". If testing is judged to be ineffective because it does not catch cheats and wastes limited resources, this presents issues for the legitimacy of other aspects of the WADA regime. For example, the whereabouts system is justified through the need for out-of-competition testing, but if testing does not work, the infringements on privacy cannot be justified, creating further legitimacy challenges. The problem of microdosing - the process of taking substances at a level that is undetectable but still induces performance gains - highlights this concern as well. As participant five who has worked closely with athletes stated,

Mostly people are only getting tested in just one hour time frame so it doesn't make so much sense because there are some substances, EPO [erythropoietin], which when you have a dose make it now very clever and sophisticated way you can avoid that one hour timeframe in which you have a level EPO in your body which leads to a positive doping test. 
It is apparent, then, that WADA's lack of attention to dealing with testing ineffectiveness to detect and deter doping is inconsistent with its stated mission. The diversion of means from developing testing has created negative consequences for evaluations of WADA's legitimacy.

\subsubsection{Investigations}

Finally, despite ineffectiveness regarding implementation and testing, WADA has actively pursued greater investigative capabilities and responsibilities due to the success of anti-doping investigations such as Lance Armstrong (Imray, 2013). Developing intelligence and investigative capabilities has contributed positively to WADA's perceived legitimacy. For example, participant eight stated, "I think it was very important decision of WADA to create the Department of Intelligence and Investigation and it was very good also to know that this department is being financed by the WADA, but it's independent of WADA". However, like the other aspects within this dimension, the positive paradigm shift to investigations was coupled with negative perceptions of the realities. For example, participant 10 noted,

It's definitely a positive step in theory, clearly. And they've had some success I think with the biathlon investigation. And also, with the Bucharest laboratory where it was a corruption case based on a whistle-blower. But I wouldn't fully trust WADA to always act on intelligence from a whistle-blower.

Highlighting concerns about data protection, the investigative competency of international federations and NADOs, cost, lack of public authority interest, inadequate resources, and legislation were all stressed as problems for investigations. The range of concerns exemplifies that even though the development of investigations demonstrated attentiveness, it could also be considered impulsive as there has been a lack of consideration given to the 
means required to ensure the effectiveness of implementation. This again has undermined the legitimacy of WADA.

In summary, despite acknowledged problems, the general purpose of the Code appears to have affirmed WADA's legitimacy. Further, WADA's mission creep to developing investigative capabilities was viewed positively, despite potential pragmatic concerns. Conversely, due to the diversion of attention and financial means, there is tension between new activities and perceived ineffectiveness in fulfilling existing responsibilities that undermines the legitimacy of WADA.

\subsection{Representation}

The second theme, representation, covers the sub-themes of: (1) WADA's establishment, (2) athlete representation, and (3) NADO representation. In becoming the global regulator of anti-doping policy, part of WADA's responsibilities include representing stakeholders in policy decisions. WADA was perceived to have failed to address the emerging representation issues in policy development. As Lawrence (2008) suggests, as an INGO's responsibilities and means increase, its legitimacy is partly determined by the extent to which stakeholders perceive that they have influence over its agenda and direction. Therefore, as WADA's operations and means have increased, perceived democratic deficits in governance and representation have created challenges for its perceived legitimacy to regulate anti-doping. Especially from evaluators who perceive that they are not adequately represented in governance processes.

\subsubsection{WADA's Establishment}

There is an important distinction to note in judgements of the legitimacy of WADA regarding representation and mission creep. Participants expressed a consensus that WADA's 
original governance approach was considered a legitimate approach to anti-doping. It is WADA's current balance of stakeholder representatives in governance processes and perceived failure to include new stakeholders emerging in the field over time that has negatively impacted its legitimacy. Having been involved with anti-doping since WADA's creation, participant five captured this change in perception stating, "I think WADA was at the very beginning a very good idea but it's now more or less holding the hands of sports lobbyists". This was echoed by participant 11 who stated, "I think the model was really unique and it's well intended but the reality today is that there are some bad imbalances that need to be looked at". These quotes illustrate the challenge of mission creep as a lack of response to representation issues has undermined the organisation's legitimacy.

Equally, participants with experience of anti-doping efforts prior to WADA highlighted that the creation of the agency has strengthened the fight against anti-doping over the last twenty years compared to previous efforts. As participant seven highlighted "some people have come into sport since that era [pre-WADA], don't remember a time before there was WADA, I do. And I think that what we've got now is very much better than what we had before". Participant one, who also had pre-WADA experience agreed, stating "It was the right way to go and I would say the right way because previously anti-doping was left to sports organisations. And yet the same sports had the duty of presenting their best athletes for competition". Both of these statements suggest that anti-doping efforts were compromised by sports organisations self-regulating themselves. This view affirms that removing sole responsibility for anti-doping from sport organisations and creating a hybrid governance structure was legitimate.

Participants who had been previously responsible for Code implementation noted that a benefit of WADA's original governance structure was the creation of bureaucratic directions for professionals. Participant 11 stated "Without WADA I don't know where we 
would have been, without a harmonised set of rules. We would not have succeeded to the degree that we, granted, have succeeded". Participant seven also emphasised how the system exists to protect clean athletes, not just catch doping athletes stating, "You have to have those procedures to protect the innocent and you have to make sure that your procedures are followed, if not the guilty will challenge them and will win on procedural inconsistencies". The evidence provided in this sub-theme situates the relationship between representation, mission creep and the legitimacy of WADA for the rest of the theme. WADA's original structure was typically perceived as legitimate, but its legitimacy has been challenged because of how the organisation has responded to the issue of representing new stakeholders over time as its' responsibilities and available resources has changed.

\subsubsection{Athlete Representation}

A common concern raised was the lack of athlete representation in governance processes, despite the protection of athletes and clean sport being the fundamental reason underlining WADA's mission. Speaking from prior experience as an athlete, participant two highlighted that athletes wanted representation as they were disillusioned with recent WADA decisions, stating: "Some clean athletes don't believe WADA because it looks like WADA didn't do anything with Russia”. Further, participant six perceived that athletes had no say in

anti-doping policy because they did not contribute financially, stating "We get no say because actually we don't fund them". These comments highlight that WADA's behaviour may be influenced by the means a source can provide, and that without appropriate athlete representation within the WADA governance structure, WADA is not responding appropriately to the changing field.

There was consensus between participants that athletes should be represented in some form, for example, participant five stated, "what is good idea is that we could improve the 
influence of athletes in general because the athletes are the most important part of sports. Without athletes' sport wouldn't work". However, the general agreement was contrasted by the variety of specific ways in which athletes should be represented. The existing athlete commissions lacked legitimacy because they were appointed rather than elected and do not have voting rights. For instance, participant six stated, "There's the WADA athlete commission. But it feels like they've got no power". Player Unions and collective bargaining were highlighted by multiple participants with experience of anti-doping governance as a model that may be suitable for democratically electing representatives and improving representation. Participant 12 argues that collective bargaining would allow athletes to determine what they believe is an appropriate punishment, relative to the sport, which is fairer than the current system. The development of player unions is relatively new and was not a factor when creating WADA's original governance structure, as highlighted by participant four who has worked in athlete representation stated, "With the exception of football [soccer] players and rugby and cricket, those sort of sports where there's now a global kind of representative bodies, they didn't really exist going back about 20 years ago". The need for WADA to respond to athlete unionisation is a key issue going forward for the organisation's legitimacy.

Other participants argued that collective bargaining could weaken anti-doping policies and, furthermore, representing such a diverse group of athletes would be complex and difficult. For example, participant 10 stated "If you look at the model in American professional sport where you have very powerful players associations, they are very good lobbyists, basically have played a key role in making sure that doping cases aren't really punished". The dilemma posed by our analysis then is whether a system that reduced punishments would be more justifiable if voted for by athletes than the current system which athletes are forced to accept. Ultimately, the answer will emerge through greater dialogue and 
representation with athletes. This is well summarised by participant nine who highlighted, "How do we better involve clean athletes in the work that we do in anti-doping to make sure that their views are heard and taken into account because they have been very unfairly excluded from the whole process".

\subsubsection{NADO Representation}

Related to athlete representation were concerns over the lack of response to growing demands for NADO and RADO representation, particularly among those who have experience working with anti-doping organisations. Like the awareness that player unions have expanded in WADA's lifetime, there was also only a handful of NADOs when WADA was created. WADA has helped develop a global network of NADOs who now act as key implementers of policy, but they have no formal representation. Similarly, WADA has encouraged the creation of RADOs tasked with coordinating nations in regions where antidoping is developing to improve policy implementation. Nevertheless, as participant 11 stated, "The whole development of NADOs around the world and the establishment of strong NADOs has occurred since the structure of WADA was decided". Equally, participant three stated, "Right now we have 15 RADOs all over the world, working with about 131 countries, if the people talk so much very loudly about levelling the playing field, they must also support the RADOs". The lack of involvement of NADOs and RADOs in governance decisions related to anti-doping policy was judged to negatively impact the legitimacy of WADA. This is again expected from Lawrence's (2008) perspective, as WADA's mission has crept and it has gained new means since its inception, its governance structure has not responded to the emergence of the NADOs and RADOs responsible for implementing policy.

To summarise, the data in this theme highlights that WADA's original governance structure was viewed as legitimate. Yet the tension between the lack of response to growing 
demands for representation in regulating anti-doping from different stakeholders against the backdrop of WADA's increasing responsibilities and means was evaluated negatively (regardless of performance or sufficiency of means), thus undermining the legitimacy of WADA.

\subsection{Conflicts of Interest}

The final theme, conflicts of interest, consists of two sub-themes: (1) financial, and (2) governance, which explore how WADA's mission creep, effectiveness and means are influenced by the inherent complexity of sport and WADA's dependence on stakeholders due to its 'top-down' approach to implementation (Gray, 2019).

\subsubsection{Financial}

WADA currently receives funding from all government signatories which is matched by the IOC. The perceived problem with this arrangement is that by being the major contributor of financial means, the IOC retains a controlling stake in WADA. Therefore, there is an incentive for WADA to prioritise the IOC's expectations of legitimate behaviour. Moreover, the regular replacement of government representatives on WADA's Executive Committee compared to consistency in IOC representation is a significant complicating factor. As participant nine noted, "The IOC as you know was funding half of WADA and it still does to this day. And that means in a sense it keeps a stranglehold because of the continuity in personnel". These perceptions mirror previous research that has shown how the behaviours of WADA, and therefore the organisation's creep, is unduly influenced by seeking to remain legitimate in the eyes of the IOC to secure means instead of maximising effectiveness (Read et al., 2019). 
This issue of funding dependency links to the perception that WADA is underfunded. The outcome of underfunding is that WADA is both unable to fully execute its responsibilities and must expand its mission (i.e. creep) as an organisation to retain legitimacy and ensure that it retains access to the limited resources it currently possesses. These negative evaluations of funding were exacerbated by perceptions based on previous experiences of working with sports organisations that there are adequate resources within the sports ecosystem to remedy WADA's lack of means, but no inclination among stakeholders to do so. It was perceived that some WADA signatories are under conflicting pressures to: (1) promote and monetise their sport to fund organisational activities, and (2) support anti-doping which could undermine a sports' image if doping is exposed. As participant 13 stated "At least in the past, some organisations, I'm not saying they don't care about anti-doping, but it is not their priority". Likewise, participant 11 stated, "We now know that there have been issues with international federations having less of an interest to actually combat doping in their sport because it also affects their business". Evidently, our analysis suggests that both WADA's lack of resources, the ineffectiveness generated by potentially conflicted signatories implementing policy, and dependence on IOC funding undermined WADA's legitimacy.

Yet, for all the concerns about underfunding there was a perception that WADA's legitimacy would not necessarily be improved solely by the provision of more money. Participant three noted,

It's not simply a question of giving WADA more money because you can give an organisation more money and more resources, but still if they don't have the power, if they don't have strategic focus, if the governance issues are not dealt with, if the voice of the athlete is not coming to the fore, then we have major issues. 
This statement captures Lawrence's (2008) dilemma for INGO's. If more resources were provided to WADA due to concern about underfunding, reliance on IOC funding, and the impact this has on decision making processes, then WADA's legitimacy in other areas would come under greater scrutiny. Overall, WADA's funding situation presents a legitimacy tension between WADA's insufficient means to achieve its mission and the influence of the IOC over how WADA prioritises concerns when making-decisions.

\subsubsection{Governance}

Conflicts of interest in governance applies to both Olympic Movement representatives and national government representatives involved in anti-doping. As the two primary groups responsible for decision-making at WADA, participants with experience from sporting organisations and governmental organisations involved in anti-doping recognised that representatives with competing objectives may undermine WADA's effectiveness. For example, participant five argued,

Very very very clear that there are different stakeholders in sports who have their own interests in order to promote each sport and to make business from sports and that interferes with its task to challenge or to fight against doping in sports because doping is a part of sports and helps to improve performance and performances are good for money.

Participant 10 captured how it relates to financial conflict of interest stating, "For the IOC the most important thing is the commercial popularity of the Olympics, they're not really prepared to really expose doping and punish sports doping if they're still raking in good sponsorship and television revenue". These quotes suggest that WADA's ineffectiveness at dealing with doping was linked to potentially conflicted governance with some stakeholders 
primarily concerned that anti-doping should not interfere with monetising elite sport, therefore, undermining WADA's legitimacy to regulate the issue.

National government representatives were perceived to be equally conflicted because of the benefits that international sporting success can offer to a government. For example, participant 10 stated, “it's basically not in the interests of either party that funds WADA for doping to really be fully penetrated because it would reflect badly on most of the sports and a lot of the countries who are funding it". There was a collective perception between participants that any individual in WADA's Executive Committee (i.e., the main decisionmaking body of WADA) should not hold multiple interests either with a sport organisation or national government. Until this is achieved the organisation would continue to be ineffective in fulfilling its mission and, therefore, lacking legitimacy in the eyes of some stakeholders. These concerns reflect a general perception that decisions taken by WADA may not necessarily be motivated by a desire to fully support anti-doping but rather to superficially manage the issue.

In summary, there is a clear tension for WADA's legitimacy between the lack of resources, the need to retain legitimacy in the eyes of the IOC, and overall effectiveness. It is also recognised that perceived conflicts of interest in the governance structure cannot be considered independent of the evaluator's role, the issues the organisation prioritises and the subsequent support and means WADA receives.

\section{Mission Creep at WADA}

From this exploratory study of how WADA's mission creep, means and effectiveness have influenced its legitimacy to regulate anti-doping globally, three distinct themes emerged: (1) code implementation, (2) representation, and (3) conflicts of interest. Collectively, the data and analysis suggest that WADA's legitimacy is strongly influenced by 
resource scarcity (i.e., means), resource justification (i.e., responsiveness) and resource utilisation (i.e., effectiveness). The deliberate decision to pursue new activities without addressing existing priorities suggests a greater concern with being perceived as legitimate and retaining access to the limited means it commands than technical efficiency.

When first established, WADA's original structure and mission was, and is still, perceived as legitimate. Participants highlighted that by separating anti-doping responsibilities from sport organisations and helping create a formal regulatory structure, the establishment of WADA was beneficial. This finding adds nuance to Lawrence's (2008) theorisation of mission creep. Lawrence suggested that ineffectiveness due to mission creep undermines INGOs legitimacy to govern. The evidence presented illustrates that WADA's legitimacy is buffered by the perception that an agency that is considered to be at least partially ineffective but which is also considered to have the capacity to develop is preferable to the previously fragmented regulatory approach. This does not mean an INGO is immune from legitimacy challenges due to ineffectiveness, but historical improvement may provide some protection. There is also the need to consider why an ineffective INGO might be perceived as preferable and by whom. It is possible that an ineffective INGO could retain legitimacy if the regulatory environment suits key stakeholders.

Despite the buffer provided by comparisons to previous anti-doping regulation arrangements, WADA's legitimacy has still been challenged by perceptions of ineffectiveness relating to its core mission of harmonising anti-doping policy and that WADA is diverting its limited means to other priorities. Our analysis clearly identifies that WADA's legitimacy cannot be separated from the tension it faces between trying to secure means, effectively executing existing and new responsibilities, and appearing responsive to emerging challenges in anti-doping. This creates a paradox for WADA as it must engage in mission creep to appear responsive and retain its legitimacy in order to justify the means it receives. 
The increased responsibility leads to re-allocation of means and decreased effectiveness in other responsibilities (e.g., harmonisation). Previous research has emphasised that mission creep may be a result of deliberate attempts to remain relevant and appear responsive in order to bolster perceptions of legitimacy, which necessarily means diverting resources away from other responsibilities (Kraatz \& Block, 2008; Kwong et al., 2017). The data has shown resource diversion generates negative perceptions of legitimacy due to ineffectiveness in the execution of key responsibilities. This has three implications for the current regulation of anti-doping and WADA.

Firstly, facing this paradox, WADA should re-evaluate its responsibilities and priorities to simplify the activities it is responsible for to improve its effectiveness. Doping can be viewed as a 'wicked problem' meaning its causes are multifaceted, dynamic, and unclear as are the solutions rendering the complete eradication of doping unlikely (Viret, 2020). Therefore, WADA needs to address what is feasible. This could be a return to prioritising monitoring signatory compliance rather than continuing to focus on other peripheral activities such as education and amateur-level doping which could be handled by NADOs and governments. This is not to say that new responsibilities such as coordinating investigations into drug-trafficking with police organisations are not relevant to anti-doping; rather, WADA should look to evaluate its' capacity to execute all of its current responsibilities in relation to its core purpose for existence. Determining what responsibilities WADA should prioritise presents a significant challenge given the diversity of stakeholders in anti-doping. Secondly, WADA's budget is gradually increasing until 2022 (WADA, 2018); however, the organisation should seek to obtain increased means from other sources to more effectively execute its responsibilities and reduce its reliance on the IOC. Lastly, reevaluation of capacities and priorities as well as efforts to increase resource availability and 
financers should be accompanied by improvement in representation as expectations of democratic governance accompany increased means allocations (Lawrence, 2008).

\section{Conclusion}

Applying Lawrence's (2008) INGO legitimacy dilemma, the purpose of this research was to explore how anti-doping professionals perceive the relationship between WADA's mission creep, means, effectiveness, and legitimacy. Following a constructivist paradigm that privileges participant context, the data and analysis have shown that the legitimacy of WADA is vulnerable due to the reality that the organisation must remain responsive to its environment if it is to remain legitimate and maintain access to resources. Yet, in being responsive, WADA lacks the means to be effective across its expanding responsibilities. This conundrum creates challenges for WADA as a lack of perceived legitimacy to govern and regulate anti-doping due to the stretching of means leads to a lack of behavioural support from key stakeholders (Bitektine \& Haack, 2015; Klein, Schneider \& Spieth, 2020). As such, the findings from this research make a significant theoretical contribution by developing Lawrence's (2008) dilemma and providing an initial set of theoretically grounded and empirically supported themes to understand how anti-doping professionals evaluate the legitimacy of WADA.

The data from this research supports two implications for the practical management of anti-doping. First, WADA should re-evaluate the range of responsibilities it currently has jurisdiction over and consider where its limited means would be best allocated, rather than trying to stretch resources. Second, at present WADA is required to continually justify its relevance and promote the importance of anti-doping (Toohey \& Beaton, 2017). If WADA were able to identify a long-term guaranteed funding platform that reduced its dependence on the IOC, greater effort could be invested on remedying the harmonisation issues highlighted 
that are central to its mission. However, it is naïve and irresponsible to propose greater funding and ignore the criticisms about the lack of response to representation of athletes, NADOs and RADOs as well as the current conflicts of interest. To improve behavioural support, any proposed changes to funding should be accompanied by changes in governance structure that improve representation, accountability and transparency.

Future research might use theses novel themes for the study of WADA's legitimacy and support from anti-doping professionals. For example, a questionnaire of NADO staff based on these themes would help understand the level of support for WADA. Future research might also explore alternative means, for example, an exploratory study of Olympic sponsors would provide insight into how WADA might go about discussing financial support with these stakeholders.

In closing, WADA's tensions highlight the challenge for other sport organisations operating with limited means. The potential gains that accompany mission creep must be balanced against the legitimacy challenges presented by increased scrutiny of governance systems, diverting resources to new responsibilities and the potential for reduced effectiveness.

\section{References}

Andrade, A. D. (2009). Interpretive research aiming at theory building: Adopting and adapting the case study design. The Qualitative Report, 14(1), 42-60.

Beetham, D. (2013). The Legitimation of Power (2 ${ }^{\text {nd }}$ Edition). Macmillan International Higher Education.

Berger, P. L., \& Luckmann, T. (1967). The social construction of reality: A treatise in the sociology of knowledge (No. 10). Penguin UK. 
Bitektine, A. (2011). Toward a theory of social judgments of organizations: The case of legitimacy, reputation, and status. Academy of Management Review, 36(1), 151-179.

Bitektine, A., \& Haack, P. (2015). The "macro" and the "micro" of legitimacy: Toward a multilevel theory of the legitimacy process. Academy of Management Review, 40(1), $49-75$.

Bloodworth, A., \& McNamee, M. (2010). Clean Olympians? Doping and anti-doping: The views of talented young British athletes. International Journal of Drug Policy, 21(4), 276-282.

Braun, V., \& Clarke, V. (2006). Using thematic analysis in psychology. Qualitative Research in Psychology, 3(2), 77-101.

Clarke, V., \& Braun, V. (2013). Teaching thematic analysis: Overcoming challenges and developing strategies for effective learning. The Psychologist, 26(2), 120-123.

Deephouse, D. L., Bundy, J., Tost, L. P., \& Suchman, M. C. (2017). Organizational legitimacy: Six key questions. In Greenwood, R., Oliver, C., Lawrence, T. B., \& Meyer, R. E. (Eds.), The SAGE Handbook of Organizational Institutionalism, 27-54. Thousand Oaks, CA: Sage.

Dimeo, P., \& Møller, V. (2018). The Anti-Doping Crisis in Sport: Causes, Consequences, Solutions. London, UK: Routledge.

Donovan, R. J., Egger, G., Kapernick, V., \& Mendoza, J. (2002). A conceptual framework for achieving performance enhancing drug compliance in sport. Sports medicine, 32(4), 269-284. 
Efverström, A., Bäckström, Å., Ahmadi, N., \& Hoff, D. (2016a). Contexts and conditions for a level playing field: Elite athletes' perspectives on anti-doping in practice. Performance Enhancement \& Health, 5(2), 77-85.

Efverström, A., Ahmadi, N., Hoff, D., \& Bäckström, Å. (2016b). Anti-doping and legitimacy: an international survey of elite athletes' perceptions. International Journal of Sport Policy and Politics, 8(3), 491-514.

Erickson, K., Patterson, L. B., \& Backhouse, S. H. (2018). “The process isn't a case of report it and stop": Athletes' lived experience of whistleblowing on doping in sport. Sport Management Review, doi: https://doi.org/10.1016/j.smr.2018.12.001

Francis, J. J., Johnston, M., Robertson, C., Glidewell, L., Entwistle, V., Eccles, M. P., \& Grimshaw, J. M. (2010). What is an adequate sample size? Operationalising data saturation for theory-based interview studies. Psychology and Health, 25(10), 12291245.

Girginov, V., \& Parry, J. (2018). Protecting or undermining the integrity of sport? The science and politics of the McLaren report. International Journal of Sport Policy and Politics, 10(2), 393-407.

Gray, S. (2019). Achieving compliance with the World Anti-Doping Code: learning from the implementation of another international agreement. International Journal of Sport Policy and Politics, 11(2), 247-260.

Gucciardi, D. F., Jalleh, G., \& Donovan, R. J. (2010). Does social desirability influence the relationship between doping attitudes and doping susceptibility in athletes? Psychology of sport and exercise, 11(6), 479-486. 
Hanstad, D. V, \& Houlihan, B. (2015). Strengthening global anti-doping policy through bilateral collaboration: The example of Norway and China. International Journal of Sport Policy and Politics, 7(4), 587-604.

Harris, S., \& Houlihan, B. (2016). Competition or coalition? Evaluating the attitudes of national governing bodies of sport and county sport partnerships towards school sport partnerships. International Journal of Sport Policy and Politics, 8(1), 151-171.

Henning, A., \& Dimeo, P. (2019). Perceptions of legitimacy, attitudes and buy-in among athlete groups: a cross-national qualitative investigation providing practical solutions. The World Anti-Doping Agency. Retrieved from https://www.wadaama.org/en/resources/social-science/

Houlihan, B. (2014). Achieving compliance in international anti-doping policy: An analysis of the 2009 World Anti-Doping Code. Sport Management Review, 17(3), 265-276.

Hunt, T. M. (2011). Drug games: The International Olympic Committee and the politics of doping, 1960-2008. University of Texas Press.

Hurd, I. (1999). Legitimacy and authority in international politics. International Organization, 53(2), 379-408.

Imray, G. (2013). Four-year bans for doping cheats passed by global sports watchdog. The Record. https://www.therecord.com/

Jalleh, G., Donovan, R. J., \& Jobling, I. (2014). Predicting attitude towards performance enhancing substance use: A comprehensive test of the Sport Drug Control Model with elite Australian athletes. Journal of science and medicine in sport, 17(6), 574-579. 
Klein, S., Schneider, S., \& Spieth, P. (2020). How to stay on the road? A business model perspective on mission drift in social purpose organizations. Journal of Business Research. https://doi.org/10.1016/j.jbusres.2020.01.053

Kraatz, M. S., \& Block, E. S. (2008). Organizational implications of institutional pluralism. In R. Greenwood, C. Oliver, T. Lawrence, \& R. Meyer (Eds.), The Sage Handbook of Organizational Institutionalism (pp. 243-275). Thousand Oaks, CA: Sage.

Kwong, C., Tasavori, M., \& Wun-mei Cheung, C. (2017). Bricolage, collaboration and mission drift in social enterprises. Entrepreneurship \& Regional Development, 29(78), 609-638.

Lo Iacono, V., Symonds, P., \& Brown, D. H. (2016). Skype as a tool for qualitative research interviews. Sociological Research Online, 21(2), 1-15.

Lawrence, R. Z. (2008). International Organisations: The Challenge of Aligning Mission, Means and Legitimacy. World Economy, 31(11), 1455-1470.

Lincoln, Y. S., \& Guba, E. G. (2000). The only generalization is: There is no generalization. Case study method, 27-44.

Lock, D., Filo, K., Kunkel, T., \& Skinner, J. L. (2015). The development of a framework to capture perceptions of sport organizations legitimacy. Journal of Sport Management, 29(4), 362-379.

Loland, S., \& McNamee, M. J. (2019). The 'spirit of sport', WADAs code review, and the search for an overlapping consensus. International Journal of Sport Policy and Politics, 11(2), 325-339. 
McDermott, V. (2015). The war on drugs in sport: Moral panics and organizational legitimacy. Routledge.

Meyer, J. W., \& Rowan, B. (1977). Institutionalized organizations: Formal structure as myth and ceremony. American Journal of Sociology, 83(2), 340-363.

Nowell, L. S., Norris, J. M., White, D. E., \& Moules, N. J. (2017). Thematic analysis: Striving to meet the trustworthiness criteria. International Journal of Qualitative Methods, 16(1), doi:1609406917733847.

Opdenakker, R. (2006, September). Advantages and disadvantages of four interview techniques in qualitative research. Forum: Qualitative Social Research, 7(4).

Overbye, M., \& Wagner, U. (2014). Experiences, attitudes and trust: an inquiry into elite athletes' perception of the whereabouts reporting system. International journal of sport policy and politics, 6(3), 407-428.

Powell, W. W., \& Rerup, C. (2017). Opening the black box: The microfoundations of institutions. In Greenwood, R., Oliver, C., Lawrence, T. B., \& Meyer, R. E. (Eds.), The Sage Handbook of Organizational Institutionalism, 311-337. Thousand Oaks, CA: Sage.

Qvarfordt, A., Hoff, D., Bäckström, Å., \& Ahmadi, N. (2019). From fighting the bad to protecting the good: Legitimation strategies in WADA's athlete guides. Performance Enhancement \& Health, https://doi.org/10.1016/j.peh.2019.100147

Read, D., Skinner, J., Lock, D., \& Houlihan, B. (2019). Legitimacy driven change at the World Anti-Doping Agency. International Journal of Sport Policy and Politics, 11(2), 233-245. 
Saldaña, J. (2015). The Coding Manual for Qualitative Researchers. London, UK: Sage.

Suddaby, R., Bitektine, A., \& Haack, P. (2017). Legitimacy. Academy of Management Annals, 11(1), 451-478.

Toohey, K., \& Beaton, A. (2017). International cross-sector social partnerships between sport and governments: The World Anti-Doping Agency. Sport management review, 20(5), 483-496.

Tost, L. P. (2011). An integrative model of legitimacy judgments. Academy of Management Review, 36(4), 686-710.

Viret, M. (2020). Using interdisciplinary tools to improve anti-doping: Utopia or necessity?. The International Sports Law Journal, 20(1), 82-113.

WADA. (2018). WADA Foundation Board Endorses Budget Increase to Strengthen Agency’s Capacity to Deliver Clean Sport. World Anti-Doping Agency. https://www.wada-ama.org/

Waddington, I., \& Møller, V. (2014). Cannabis use and the spirit of sport: a response to Mike McNamee. Asian bioethics review, 6(3), 246-258.

Washington, M., \& Patterson, K. D. (2011). Hostile takeover or joint venture: Connections between institutional theory and sport management research. Sport Management Review, 14(1), 1-12.

Weber, C., Kamber, M., Lentillon-Kaestner, V., Krug, O., \& Thevis, M. (2015). Seizures of doping substances at the Swiss Border - a descriptive investigation. Forensic science international, 257, 359-368. 
Zucker, L. G. (1977). The role of institutionalization in cultural persistence. American Sociological Review, 726-743. 